\title{
Crystallization behavior of zeolite beta from acid-leached metakaolin
}

\author{
Li Qiang ${ }^{1,2}$, Zhang Ying ${ }^{1,3 *}$, Cao Zhijun ${ }^{1}$, Gao Wei ${ }^{1}$ and Cui Lishan ${ }^{1,3^{* *}}$ \\ ${ }^{1}$ Department of Materials Science and Technology, China University of Petroleum, Beijing 102249, China \\ ${ }^{2}$ National Key Laboratory of Multiphase Complex System, Institute of Process Engineering, Chinese Academy of Sciences, \\ Beijing 100190, China \\ ${ }^{3}$ Microstructure Laboratory for Energy Materials, China University of Petroleum, Beijing 102249, China \\ (C) China University of Petroleum (Beijing) and Springer-Verlag Berlin Heidelberg 2010
}

\begin{abstract}
Well-crystallized zeolite beta was synthesized by using acid-leached metakaolin as the silica-alumina source and tetraethylammonium hydroxide structure-directing agent. The influence of the composition of the reaction mixture on product crystallinity was investigated, and the crystallization process was studied by examining solid samples obtained at different synthesis times. Results showed that the acid-leached metakaolin was fully converted into soluble aluminum and silicon species, which is crucial for the formation of well-crystallized zeolite beta. At the beginning of the crystallization process, these soluble aluminum and silicon species formed a aluminum-rich intermediate structure with layer morphology. With the crystallization proceeding, more silicon species were incorporated into the zeolite beta framework and the layered structure was changed into spherical particles of zeolite beta with high $\mathrm{SiO}_{2} / \mathrm{Al}_{2} \mathrm{O}_{3}$ ratio and crystallinity.
\end{abstract}

Key words: Zeolite beta, acid-leached metakaolin, tetraethylammonium hydroxide (TEAOH), liquid phase transformation mechanism

\section{Introduction}

Porous materials such as zeolite, mesoporous silica and MOF (metal organic framework) are widely used in catalysis, adsorption, separation and bio-application (Czaja et al, 2009; Davis, 2002; Liu et al, 2009; Liu et al, 2008a; 2008b ). Zeolite beta is the first example of a three-dimensional large-pore zeolite with low aluminum content (Wadlinger et al, 1967). It has been widely used in hydrocracking, hydroisomerization, aromatic alkylation, disproportionation and other organic synthesis processes (Blasco et al, 1996). Usually, zeolite beta is synthesized by a hydrothermal method under mild conditions (Camblor et al, 1991). Besides the conventional hydrothermal method, many other methods have also been reported such as the dry gel conversion method (Hari Prasad Rao et al., 1998), steam-assisted crystallization method (Matsukata et al, 2002) and F-system synthesis (Liu et al, 2001). The silica sources used in theses methods include aqueous silica sol (Canna and Hinchey, 1992), colloidal silica (Matsukata et al, 2002), tetraethylorthosilicate (Eapen et al, 1994), granular amorphous aluminosilicate (Inoue and Hiroshi, 1995), precipitated silica (Saxton and Zajacek, 1996), fumed silica (Guo and Li, 2002) and white rice husk ash (Prasetyoko et al, 2006).

\footnotetext{
*Corresponding author. email. yingzh1997@163.com

** Corresponding author. email. 1scui@cup.edu.cn

Received January 6, 2010
}

Kaolin is one of the clay materials most widely used by human beings since ancient times. It is an ideal raw material for synthesis of low-silica zeolites, such as zeolite A (Chandrasekhar et al, 1997; Chandrasekhar and Pramada, 2008), X (Colina and Llorens, 2007), JBW, CAN, SOD, and ABW zeolites (Lin et al, 2004), because the molar contents of $\mathrm{SiO}_{2}$ and $\mathrm{Al}_{2} \mathrm{O}_{3}$ are similar with each other. Some zeolites with high $\mathrm{Si} / \mathrm{Al}$ ratios, such as mordenite (Mignoni et al, 2008), ZSM-5 (Madhusoodana et al, 2005) and Y, can also be prepared by using kaolin and additional silica sources as raw materials (Chandrasekhar and Pramada, 2004). Very recently a new method of hydrothermal synthesis of zeolite beta from acid-leached metakaolin, and the characterization and catalytic application of the as-synthesized zeolite beta were reported for the first time by our work teams (Zhang et al, 2007; Wan et al, 2009; 2010). For this new synthesis system, this paper focuses on 1) the effect of initial molar composition of the reaction mixture on product crystallinity, and 2) the crystallization behavior of zeolite beta synthesized from acid-leached metakaolin. Finally, based on the experimental results, a liquid-phase crystallization mechanism model is developed for zeolite beta synthesis using acid-leached metakaolin as silica and alumina sources.

\section{Experimental}

\subsection{Synthesis}

The Suzhou kaolin mineral (provided by CNPC Lanzhou 
PetroChemical Co., China) was first calcined at $720{ }^{\circ} \mathrm{C}$ for $4 \mathrm{~h}$ and then dealuminated with $20 \mathrm{wt} \% \mathrm{HCl}$ solution (Beijing Chemical Reagent Co., China) at $94{ }^{\circ} \mathrm{C}$ under reflux conditions to obtain the acid-leached metakaolin with a $\mathrm{SiO}_{2} /$ $\mathrm{Al}_{2} \mathrm{O}_{3}$ molar ratio of 88 . Following a typical process, $3.0 \mathrm{~g}$ of acid-leached metakaolin was added to a mixture, composed of $1.3 \mathrm{~g}$ of tetraethylammonium hydroxide solution (TEAOH, 35 wt\%, Hangzhou Gelinda Chemical Reagent Co., China) and $0.2 \mathrm{~g}$ of $\mathrm{NaOH}$ granules (96 wt \%, Beijing Chemical Reagent Co., China), to obtain the reactant mixture with the molar composition of $1.0 \mathrm{Al}_{2} \mathrm{O}_{3}: 88.0 \mathrm{SiO}_{2}: 4.5 \mathrm{Na}_{2} \mathrm{O}: 6.0$ TEAOH: $265.7 \mathrm{H}_{2} \mathrm{O}$. After being stirred for about $30 \mathrm{~min}$, the mixture was sealed into a $50 \mathrm{ml}$ stainless steel autoclave, and reacted in an oven at $140{ }^{\circ} \mathrm{C}$ for $12 \mathrm{~h}$ and then $170{ }^{\circ} \mathrm{C}$ for $14 \mathrm{~h}$. Finally, the solid product was filtered, washed with distilled water, and dried at $100{ }^{\circ} \mathrm{C}$ overnight.

\subsection{Characterization}

Powder X-ray diffraction (XRD) patterns were collected with a Rigaku D/MAX-2500 diffractometer using CuK $\alpha$ radiation and a Ni filter. Fourier transform infrared spectra (FT-IR) were recorded with a DIGLAB FTS-3000 spectrophotometer using the $\mathrm{KBr}$ wafer technique. The morphology and particle size of zeolite beta were determined by scanning electron microscopy (SEM) images taken with a CAMBRIDGE S-360 microscope. The crystallinity of zeolite beta was determined by X-ray diffraction and the crystallinity of the as-synthesized typical beta sample was designated as $100 \%$. The relative crystallinity of the other samples was calculated according to the total area of the characteristic diffraction peaks of zeolite beta at $2 \theta=7.8^{\circ}, 21.6^{\circ}, 22.6^{\circ}, 25.3^{\circ}$, $27.0^{\circ}$ and $29.6^{\circ}$ (Higgins et al, 1988). The XRD peak located at $2 \theta \approx 22.6^{\circ}$ was used to compare the $\mathrm{SiO}_{2} / \mathrm{Al}_{2} \mathrm{O}_{3}$ ratios of beta samples.

\section{Results and discussion}

\subsection{Effect of initial $\mathrm{H}_{2} \mathrm{O} / \mathrm{SiO}_{2}$ ratio on the crystallinity of zeolite beta}

Synthesis of zeolite beta was carried out by adding different volumes of water. That is, the acid-leached metakaolin, $\mathrm{NaOH}$ and TEAOH contents were held constant for all batches while the $\mathrm{H}_{2} \mathrm{O}$ content was varied. The XRD patterns of the beta samples synthesized from reaction mixtures with different initial $\mathrm{H}_{2} \mathrm{O} / \mathrm{SiO}_{2}$ ratios are shown in Fig. 1. It can be seen that well-crystallized zeolite beta was obtained when the $\mathrm{H}_{2} \mathrm{O} / \mathrm{SiO}_{2}$ ratio was 3.0. Above 3.0, the relative crystallinity of the beta sample decreased greatly with increasing water content in the reaction mixture. The increase of water amount can dilute the solution and lower the concentration of primary soluble aluminum and silicon species and finally result in few collisions between these primary species. This might lead to low nucleation and crystallization rates and therefore low crystallinity of the beta sample. However, when the $\mathrm{H}_{2} \mathrm{O} / \mathrm{SiO}_{2}$ ratio is reduced to 1.3 , the corresponding beta sample also showed weak diffraction peaks, indicating low crystallinity. The reason may be that the water amount is too small to fully dissolve the acid-leached metakaolin.

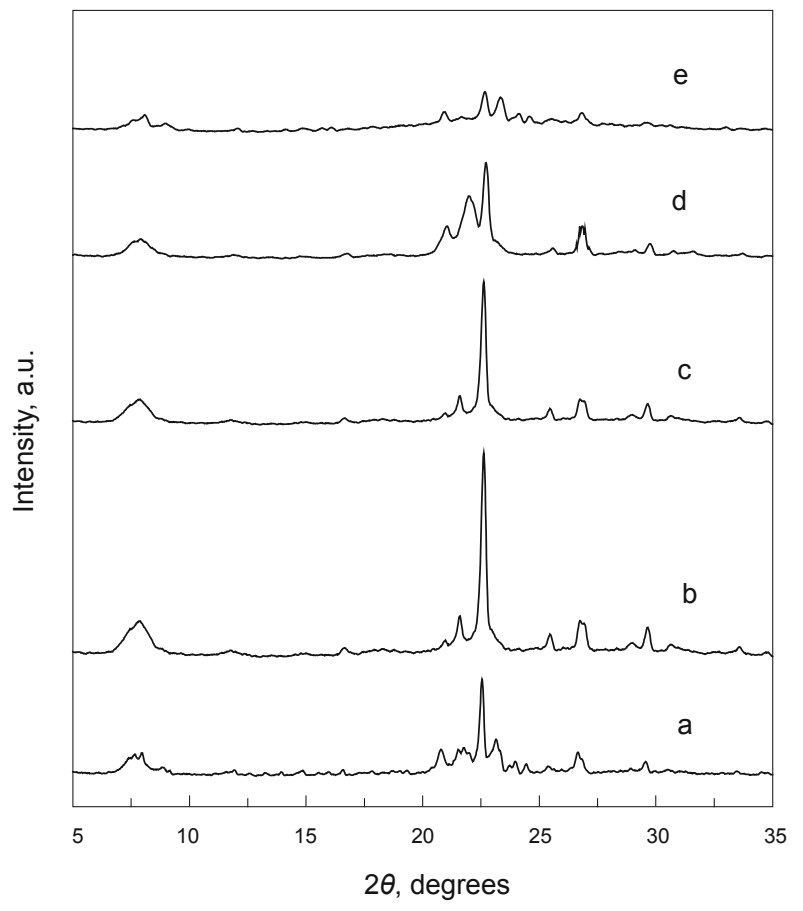

Fig. $1 \mathrm{XRD}$ patterns of beta products synthesized from the reaction mixtures with different initial $\mathrm{H}_{2} \mathrm{O} / \mathrm{SiO}_{2}$ ratios: (a) 1.3; (b) 3.0; (c) 4.0; (d) 4.5; (e) 5.0

\subsection{Effect of initial $\mathrm{Na}_{2} \mathrm{O} / \mathrm{SiO}_{2}$ ratio on the crystallinity of zeolite beta}

In this study $\mathrm{NaOH}$ solid powder was used as the alkali source and so the alkalinity of the synthesis system was related to the $\mathrm{Na}_{2} \mathrm{O} / \mathrm{SiO}_{2}$ ratio. The alkalinity of the synthesis system is one of the most important parameters to control the crystallization of zeolite. It determines the zeolite composition and is, to a great extent, responsible for zeolite type (Lechert, 1998). In general, increasing the alkalinity of the system synthesizing zeolite beta can increase overall reactivity and shorten reaction time. The effect of the $\mathrm{Na}_{2} \mathrm{O} / \mathrm{SiO}_{2}$ ratio (or the alkalinity) of the reaction mixture on the crystallinity of the beta samples is shown in Fig. 2. It can be seen that the relative crystallinity of the beta samples first increased greatly and then increased gently with the increase of the $\mathrm{Na}_{2} \mathrm{O} / \mathrm{SiO}_{2}$ ratio. The initial great increase of zeolite crystallinity might be related to the dissolution of acid-leached metakaolin. Fig. 2 shows that the minimum $\mathrm{NaOH}$ amount required for fully dissolving the acid-leached metakaolin corresponds to a $\mathrm{Na}_{2} \mathrm{O} / \mathrm{SiO}_{2}$ ratio of 0.03 . In the range of $0.03-0.06$ of $\mathrm{Na}_{2} \mathrm{O} /$ $\mathrm{SiO}_{2}$ ratio, with increasing $\mathrm{Na}_{2} \mathrm{O} / \mathrm{SiO}_{2}$ ratio, the alkalinity of the synthesis system increased but the relative crystallinity of the beta samples increased gently. Further increasing of the $\mathrm{Na}_{2} \mathrm{O} / \mathrm{SiO}_{2}$ ratio above 0.06 led to a moderate increase in the relative crystallinity of beta samples but the product yield of zeolite beta decreased because the recovered zeolite beta powder decreased by weight. So it is suggested that high alkalinity could dissolve the amorphous or/and poorly crystallized beta product, resulting in the increase of the relative crystallinity of the zeolite product.

\subsection{Effect of TEAOH amount on crystallinity of zeolite beta}

$\mathrm{TEA}^{+}$is well known as a structure directing agent in the 


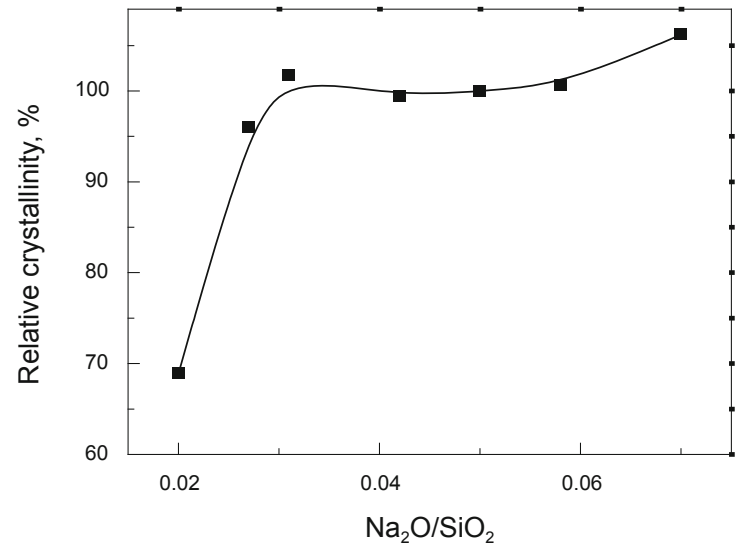

Fig. 2 The effect of initial $\mathrm{Na}_{2} \mathrm{O} / \mathrm{SiO}_{2}$ ratio on relative crystallinity of zeolite beta

synthesis of zeolite beta. It plays a crucial role in forming the zeolite beta structure. In the present work, TEA ${ }^{+}$was introduced to the synthesis system by adding TEAOH solution $(35 \mathrm{wt} \%)$ and the concomitant $\mathrm{OH}^{-}$and $\mathrm{H}_{2} \mathrm{O}$ were also introduced at the same time. Hence, the effect of TEAOH solution amount on the relative crystallinity of zeolite beta is actually the combined influence of TEA ${ }^{+}, \mathrm{OH}^{-}$and $\mathrm{H}_{2} \mathrm{O}$. As shown in Table 1, at $\mathrm{TEA}^{+} / \mathrm{SiO}_{2}$ ratio of 0.055 , the zeolite beta had the highest relative crystallinity. A small amount of TEAOH solution provides a little TEA ${ }^{+}$, which is not enough to direct the beta structure; Too large an amount of TEAOH solution contains too much $\mathrm{H}_{2} \mathrm{O}$, which can dilute the reactant and lead to poorly crystallized zeolite beta.

Table 1 The effect of TEAOH amount on relative crystallinity of zeolite beta

\begin{tabular}{ccc}
\hline $\begin{array}{c}\text { Amount of 35\% } \\
\text { TEAOH solution, g }\end{array}$ & $\mathrm{TEA}^{+} / \mathrm{SiO}_{2}$ & Relative crytallinity, \% \\
\hline 0.6 & 0.030 & 79.5 \\
1.0 & 0.055 & 108.5 \\
1.3 & 0.068 & 100 \\
1.6 & 0.082 & 93.5 \\
1.8 & 0.095 & 67.2 \\
\hline
\end{tabular}

\subsection{Crystallization mechanism}

\subsubsection{Crystallization curve}

Fig. 3 shows the S-shaped crystallization curve of a typical beta sample. The characteristic S-shaped crystallization curve of the sample can be divided into three periods: Induction period (I), crystallization period (II) and stable period (III). During the induction period (I) from $0 \mathrm{~h}$ to $4 \mathrm{~h}$, crystalline nuclei form. During the crystallization period (II) from $4 \mathrm{~h}$ to $14 \mathrm{~h}$, crystal nuclei grow rapidly in size. Finally, during the stable period (III) from $14 \mathrm{~h}$ to $27 \mathrm{~h}$, the crystallinity changes little and the crystallization is over.

In order to study the crystallization behavior in the selected time intervals based on the crystallization curve, the autoclave was immersed in cold water and its contents were filtered and washed with deionized water to $\mathrm{pH}=8-9$, and then dried at $100{ }^{\circ} \mathrm{C}$ overnight. In this way four samples were obtained, and denoted as S4, S8, S14, S24, from the reaction mixtures which were crystallized at $140{ }^{\circ} \mathrm{C}$ for $4 \mathrm{~h}, 140{ }^{\circ} \mathrm{C}$ for $8 \mathrm{~h}, 140{ }^{\circ} \mathrm{C}$ for $14 \mathrm{~h}$, and $140{ }^{\circ} \mathrm{C}$ for $14 \mathrm{~h}$ and then $170{ }^{\circ} \mathrm{C}$ for $10 \mathrm{~h}$, respectively. Before the crystallization period, there was almost no solid in the reaction mixture, indicating acidleached metakaolin was fully converted to soluble alumina and silica species. We concentrated and dried this reaction mixture to obtain a solid sample and labeled it as S0. The obtained five samples S0, S4, S8, S14, S24 were subsequently characterized by XRD, FTIR and SEM.

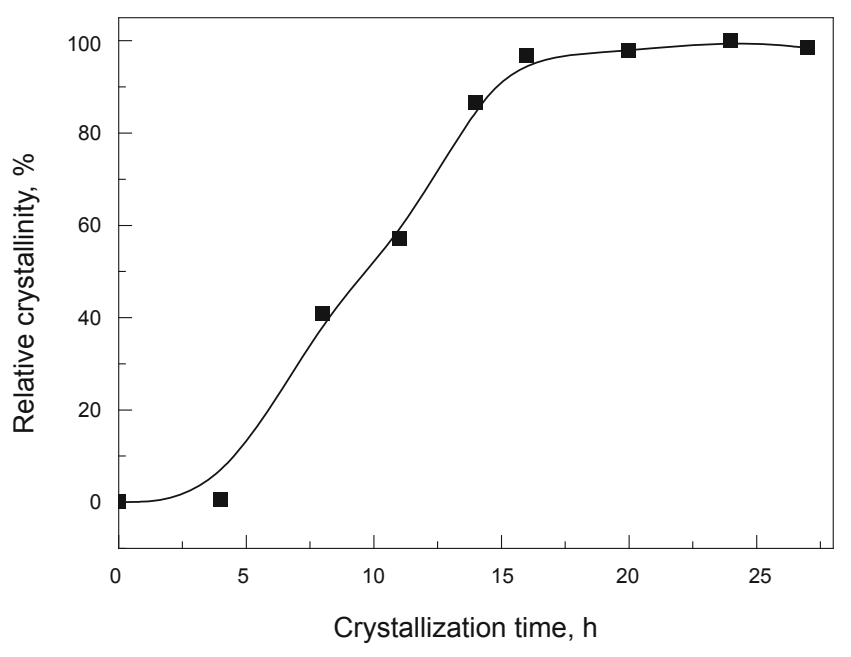

Fig. 3 The crystallization curve of the typical beta sample

\subsubsection{XRD, FTIR and SEM characterization}

The XRD, FTIR and SEM results of the samples S0, $\mathrm{S} 4, \mathrm{~S} 8, \mathrm{~S} 14, \mathrm{~S} 24$ are respectively shown in Figs. 4, 5 and 6 . The S0 sample showed no XRD diffraction peaks (see XRD pattern $a$ in Fig. 4), indicating its amorphous nature, in accordance with the irregular smooth elliptical particles shown in Fig. 6a. After $4 \mathrm{~h}$ of crystallization, the corresponding sample S4 showed three XRD peaks at $2 \theta=21.0^{\circ}, 25.0^{\circ}$ and $27.0^{\circ}$, indexed as (300), (304) and (008) crystal planes, among which the last two diffraction peaks are characteristic of beta structure. This suggests the formation of a beta structure intermediate. SEM photo of S4 shown in Fig. $6 \mathrm{~b}$ further shows that the beta structure intermediate exhibits layer morphology. After $8 \mathrm{~h}$ of crystallization, the layer structure evolved into beta particles of $200 \mathrm{~nm}$ in diameter as shown in Fig. 6c. The characteristic XRD diffraction peaks at $2 \theta=7.8^{\circ}, 21.6^{\circ}, 22.6^{\circ}, 25.3^{\circ}, 27.0^{\circ}$ and $29.6^{\circ}$ of pattern $c$ in Fig. 4 correspond to zeolite beta. The FTIR spectrum of sample S8 in pattern $c$ in Fig. 5 shows three adsorption bands at 618,568 and $525 \mathrm{~cm}^{-1}$ respectively, corresponding to the 4-membered rings, 5-membered rings and 6-membered rings of the beta structure. When the crystallization time was $14 \mathrm{~h}$, the beta structure was well developed and the characteristic XRD peak of zeolite beta become intense(see pattern $d$ in Fig. 4). Correspondingly, the FTIR spectrum of the sample S14 at 618,568 and $525 \mathrm{~cm}^{-1}$ shows the characteristic adsorption 
bands of beta structure (pattern $d$ in Fig. 5). The SEM photo in Fig. 6d shows that the beta particles size increases to 320 $\mathrm{nm}$. Further crystallization at $170{ }^{\circ} \mathrm{C}(443 \mathrm{~K})$ from $14 \mathrm{~h}$ to 24 $\mathrm{h}$ the crystallinity of the product changed little (pattern $e$ in Fig. 4) and the beta particle size increased a little to $350 \mathrm{~nm}$ (Fig. 6e), indicating that the crystallization of beta structure was almost completed at $14 \mathrm{~h}$. The XRD peak at $2 \theta \approx 22.6^{\circ}$ was used to analyze the change of $\mathrm{SiO}_{2} / \mathrm{Al}_{2} \mathrm{O}_{3}$ ratio during the crystallization process. Because the more aluminum that

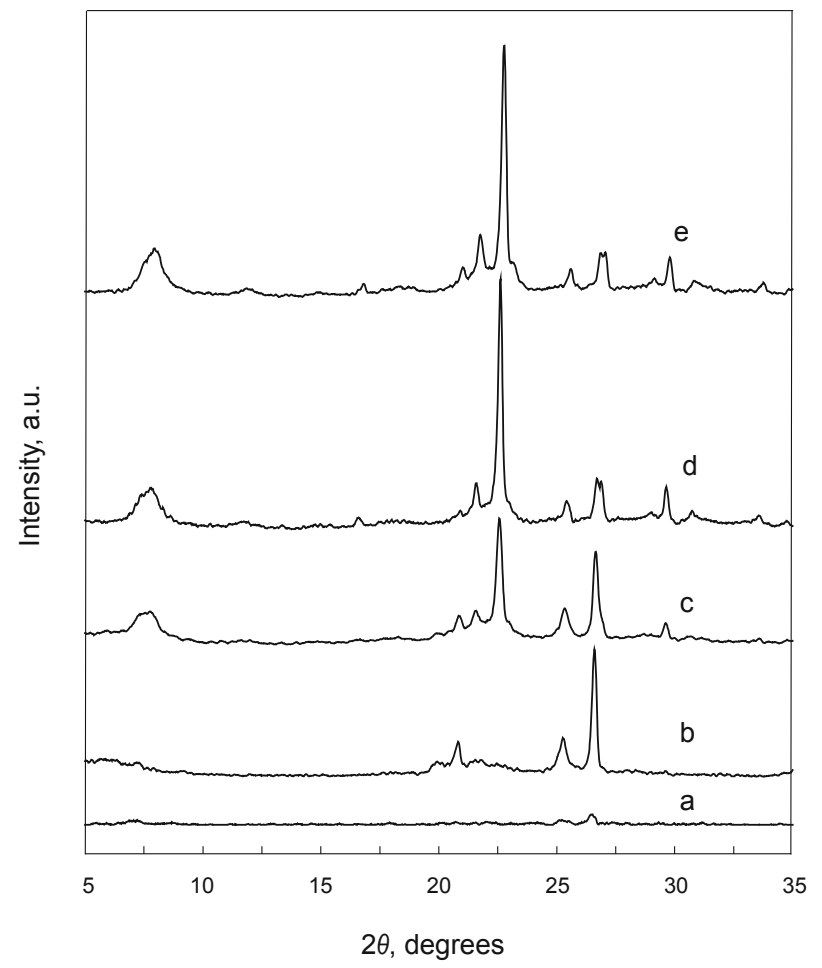

Fig. 4 The XRD patterns of the samples: (a) S0; (b) S4; (c) S8; (d) S14 and (e) S24 exists in the unit cell, the larger the unit cell and plane space, and the smaller the XRD angle. That is, a larger $\mathrm{SiO}_{2} / \mathrm{Al}_{2} \mathrm{O}_{3}$ ratio corresponds to a smaller unit cell size and thus larger XRD angles. It can be seen from Fig. 7 that the characteristic XRD peaks of S4, S8, S14, S24 are respectively located at $2 \theta \approx 22.57^{\circ}, 22.61^{\circ}, 22.67^{\circ}, 22.68^{\circ}$. The characteristic XRD peak gradually shifts to a larger XRD angle indicating the increasing $\mathrm{SiO}_{2} / \mathrm{Al}_{2} \mathrm{O}_{3}$ ratio of the beta sample. Sample $\mathrm{S} 4$ had the lowest $\mathrm{SiO}_{2} / \mathrm{Al}_{2} \mathrm{O}_{3}$ ratio and highest aluminum content. With the crystallization proceeding from $4 \mathrm{~h}, 8 \mathrm{~h}$ to $14 \mathrm{~h}$, more silica species were incorporated into beta framework resulting in a rapid increase of the $\mathrm{SiO}_{2} / \mathrm{Al}_{2} \mathrm{O}_{3}$ ratio. Further crystallization from $14 \mathrm{~h}$ to $24 \mathrm{~h}$, changed the $\mathrm{SiO}_{2} / \mathrm{Al}_{2} \mathrm{O}_{3}$ ratio only slightly. It is clear that during the crystallization period (II) from $4 \mathrm{~h}$ to $14 \mathrm{~h}$, the beta structure, morphology and $\mathrm{SiO}_{2} / \mathrm{Al}_{2} \mathrm{O}_{3}$ ratio all developed enormously.

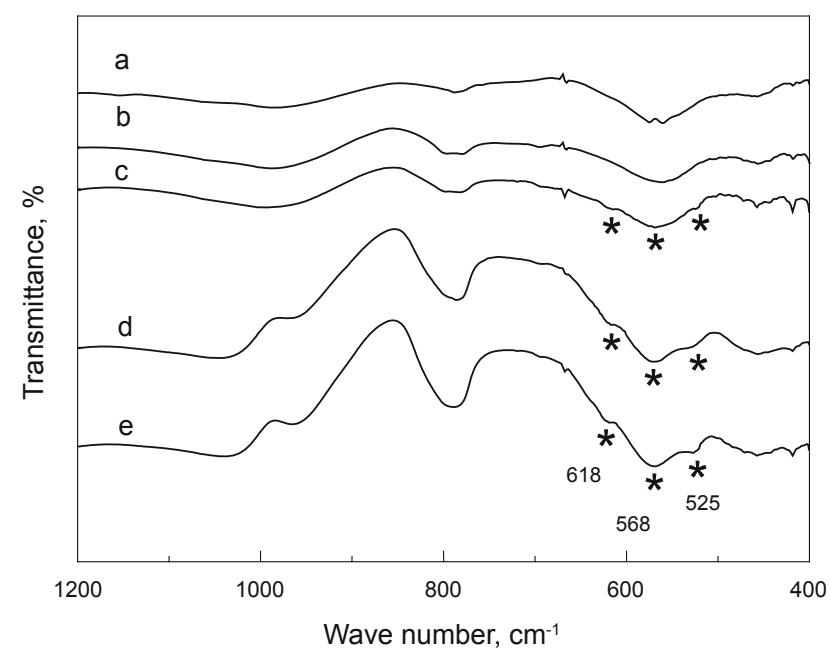

Fig. 5 FT-IR spectra of the samples: (a) S0; (b) S4; (c) S8; (d) S14 and (e) S24
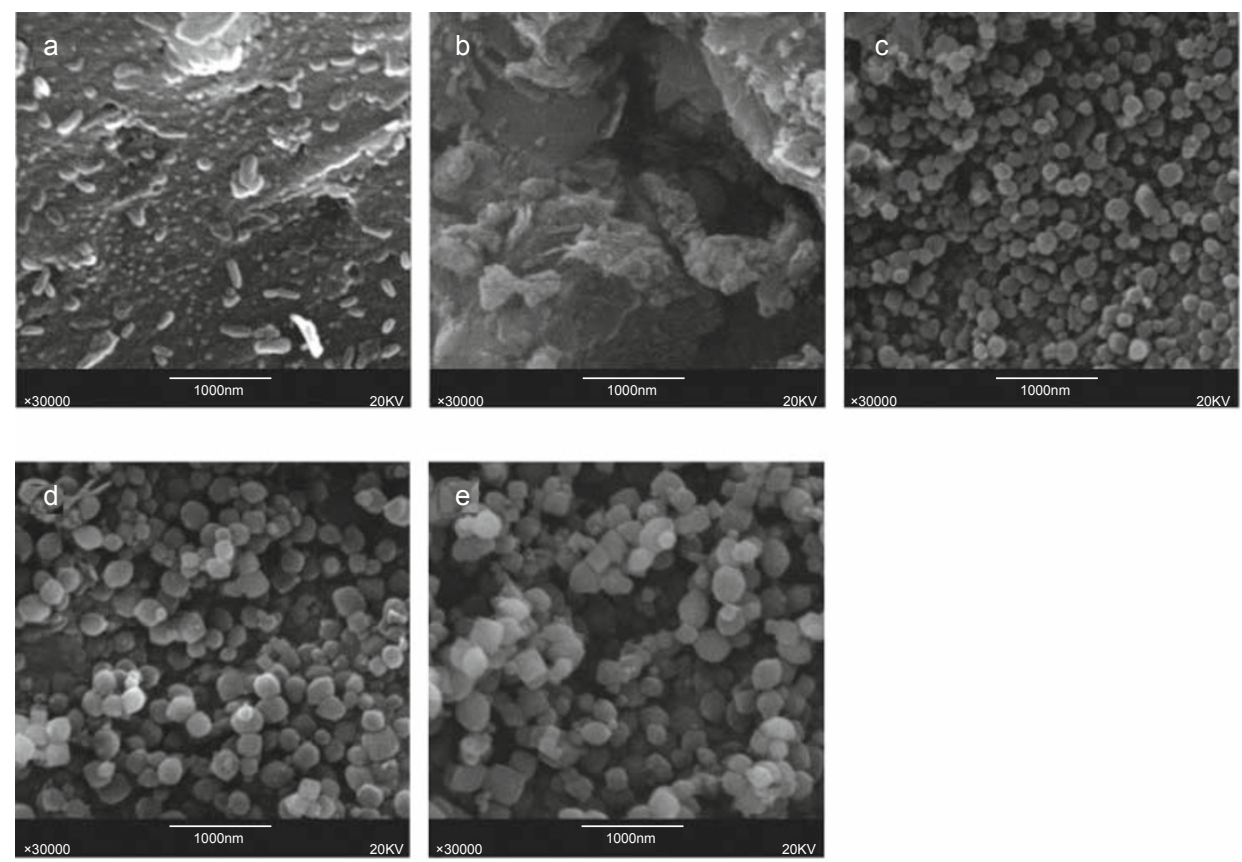

Fig. 6 SEM photos of the samples: (a) S0; (b) S4; (c) S8; (d) S14 and (e) S24 


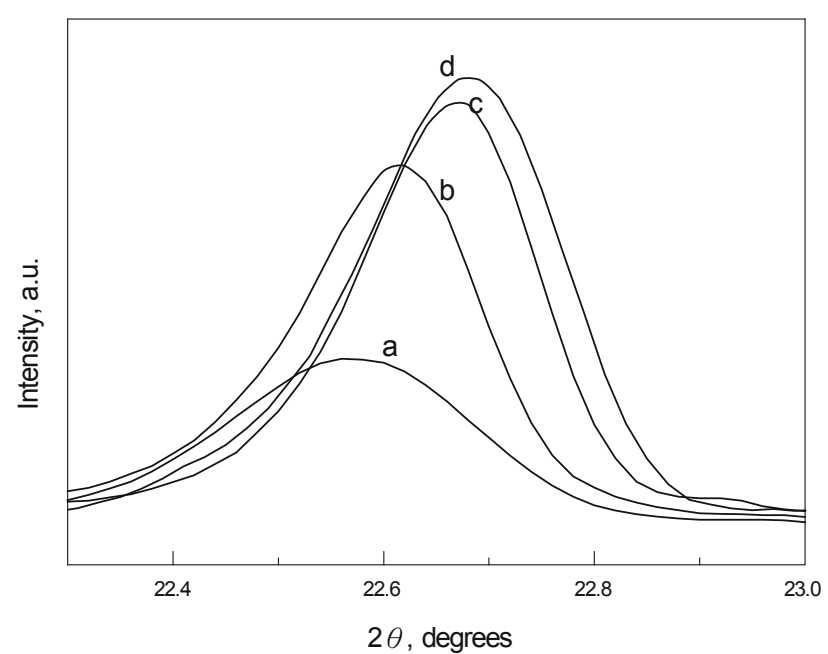

Fig. 7 The XRD patterns between $2 \theta=22.3^{\circ}$ and $23.0^{\circ}$ of the samples: (a) S4; (b) S8; (c) S14 and (d) S24

\subsubsection{Discussion of crystallization mechanism}

Based on the above results, it is suggested that the crystallization of zeolite beta from acid-leached metakaolin follows a liquid transformation mechanism. The acid-leached metakaolin first dissolves in the reaction mixture containing $\mathrm{NaOH}$ and TEAOH solution to become soluble aluminum and silicon species. Then the tetrahedral aluminum oxide $\left(\mathrm{AlO}_{4}^{-}\right)$ with negative charges arranges around the $\mathrm{TEA}^{+}$cations due to electrostatic interaction to form the beta structure intermediate with low $\mathrm{SiO}_{2} / \mathrm{Al}_{2} \mathrm{O}_{3}$ ratio. This aluminum-rich beta structure intermediate possesses three well-developed (300), (304) and (008) crystal planes and layer morphology. Afterward, with the crystallization proceeding, more soluble silica species are incorporated into the beta structure and the other crystal planes begin to develop. Simultaneously, the layered intermediates are changed into beta particles with increasing size. Finally, all the beta crystal planes are well developed, the fully crystallized zeolite beta structure forms and large beta particles are obtained.

For the zeolite crystallization from kaolin-based raw materials, the prior dissolution and gel formation steps, are the key factor for the purity and quality of the zeolite. Colina and Llorens (2007) studied the dissolution of dealuminated kaolin with a $\mathrm{SiO}_{2} / \mathrm{Al}_{2} \mathrm{O}_{3}$ molar ratio of 2.4-2.9 in sodium and potassium hydroxides during the gel formation in zeolite $\mathrm{X}$ synthesis. For dealuminated kaolin with a BET surface area of $12-37 \mathrm{~m}^{2} / \mathrm{g}$ and a micropore volume of $0.02-0.1 \mathrm{~cm}^{3} / \mathrm{g}$, the dissolution curve at $70{ }^{\circ} \mathrm{C}$ showed maximum yields of soluble $\mathrm{Si}$ and Al species of 0.5-0.6 and 0.04-0.05, respectively. In our work, the dealuminated kaolin through acid leaching has a much higher $\mathrm{SiO}_{2} / \mathrm{Al}_{2} \mathrm{O}_{3}$ molar ratio, 88 , a BET surface area of $297 \mathrm{~m}^{2} / \mathrm{g}$ and a micropore volume of $0.05 \mathrm{~cm}^{3} / \mathrm{g}$. According to the results reported by Labrid and Duquerroix (1991) that kaolin samples with higher specific surface area will result in higher Si yield and the fact that Si species in kaolin are more sensitive to alkali attack than alumina, it can be well understood that the acid-leached metakaolin with high $\mathrm{SiO}_{2} / \mathrm{Al}_{2} \mathrm{O}_{3}$ molar ratio and large BET surface area used in our work is fully converted into soluble silicon and aluminum species.

At the beginning of crystallization, the soluble silicon and aluminum species first arrange around the TEA ${ }^{+}$cations to form a beta structure intermediate with three well-developed (300), (304) and (008) crystal planes and layer morphology. Usually, the intermediate in the zeolite crystallization period made from kaolin or metakaolin (Lin et al, 2004; Akolekar et al, 1997), and in the common zeolite beta synthesis systems (Serrano et al, 2001), is X-ray amorphous. This beta structure intermediate with layer appearance may be related to the peculiar nature of acid-leached metakaolin, because the nature of raw materials used in the synthesis of a zeolite is a key factor influencing type, crystallinity and properties of zeolite. In addition, the beta structure intermediate is rich in aluminum and has a low $\mathrm{SiO}_{2} / \mathrm{Al}_{2} \mathrm{O}_{3}$ ratio. With increasing crystallization time, the $\mathrm{SiO}_{2} / \mathrm{Al}_{2} \mathrm{O}_{3}$ ratio of beta samples increases. This result is accordance with that reported in literature (Akolekar et al, 1997).

\section{Conclusions}

Well-crystallized zeolite beta has been synthesized from acid-leached metakaolin used as silica-alumina source under the templating of TEAOH. The influence of the initial reaction composition has been investigated and results show the dissolution of acid-leached metakaolin is crucial for the formation of well-crystallized zeolite beta products. Analyses of the solid samples obtained at different crystallization times show a layered aluminum-rich beta structure intermediate forms first and then develops into beta particles with higher $\mathrm{SiO}_{2} / \mathrm{Al}_{2} \mathrm{O}_{3}$ ratios and crystallinity. Finally, a liquid phase transformation mechanism is proposed demonstrating zeolite structure development, $\mathrm{SiO}_{2} / \mathrm{Al}_{2} \mathrm{O}_{3}$ ratio evolution and morphology change during the beta crystallization process from acid-leached metakaolin.

\section{Acknowledgements}

This work was financially supported by Beijing Natural Science Foundation (Grant No.2093043) and the National Natural Science Foundation of China (Grant No.20606038).

\section{References}

Akolekar D, Chaffee A and Howe R F. The transformation of kaolin to low-silica X zeolite. Zeolites. 1997. 19: 359-365

Blasco T, Camblor M A, Corma A, et al. Unseeded synthesis of Al-free Ti-beta zeolite in fluoride medium: A hydrophobic selective oxidation catalyst. Chemical communications. 1996. 20: 2367-2368

Camblor M A, Mifsud A and Perez-Pariente J. Influence of the synthesis conditions on the crystallization of zeolite Beta. Zeolites. 1991. 11(8): 792-797

Canna T R and Hinchey R J. Synthesis of zeolite Beta. US Patent 5139759. 1992

Chandrasekhar S and Pramada P N. Kaolin-based zeolite Y, a precursor for cordierite ceramics. Applied Clay Science. 2004. 27(3-4): 187198

Chandrasekhar S and Pramada P N. Microwave assisted synthesis of zeolite A from metakaolin. Microporous and Mesoporous Materials. 2008. 108(1-3): 152-161

Chandrasekhar S, Raghavan P, Sebastian G, et al. Brightness improvement studies on 'kaolin based' zeolite 4A. Applied Clay 
Science. 1997. 12(3): 221-231

Colina F G and Llorens J. Study of the dissolution of dealuminated kaolin in sodium-potassium hydroxide during the gel formation step in zeolite X synthesis. Microporous and Mesoporous Materials. 2007. 100(1-3): 302-311

Czaja A U, Trukhan N and Muller U. Industrial applications of metalorganic frameworks. Chemical Society Reviews. 2009. 38(5): 12841293

Davis M E. Ordered porous materials for emerging applications. Nature. 2002. 417: 813-821

Eapen M J, Reddy K S N and Shiralkar V P. Hydrothermal crystallization of zeolite beta using tetraethylammonium bromide. Zeolites. 1994. 14: $295-302$

Guo W P and Li Q Z. Convenient synthesis of zeolite beta in basic media without alkali metal cations. Chemistry Letters. 2002. 31: 532-534

Hari Prasad Rao P R, Ueyama K and Matsukata M. Crystallization of high silica BEA by dry gel conversion. Applied Catalysis A: General. 1998. 166: 97-103

Higgins J B, Lapierre R B, Sohlenker J L, et al. The framework topology of zeolite Beta. Zeolite. 1988. 8: 446-448

Inoue T and Hiroshi W. Method of producing zeolite Beta. US 5427765. 1995

Labrid J and Duquerroix J P. Thermodynamic and kinetic aspects of the dissolution of quartz-kaolinite mixtures by alkalis. Oil \& Gas Science and Technology. 1991. 46(1): 41-58

Lechert $\mathrm{H}$. The $\mathrm{pH}$ value and its importance for the crystallization of zeolites. Microporous and Mesoporous Materials. 1998. 22(4): 519523

Lin D C, Xu X W, Zuo F, et al. Crystallization of JBW, CAN, SOD and ABW type zeolite from transformation of meta-kaolin. Microporous and Mesoporous Materials. 2004. 70(1-3): 63-74

Liu R, Wang X, Zhao X, et al. Sulfonated ordered mesoporous carbon for catalytic preparation of biodiesel. Carbon. 2008a. 46: 1664-1669

Liu R, Zhang Y and Feng P. Multi-responsive supramolecular nanogated ensembles. Journal of the American Chemical Society. 2009. 131: 15128-15129

Liu R, Zhao X, Wu T, et al. Tunable redox-responsive hybrid nanogated ensembles. Journal of the American Chemical Society. 2008b. 130: 12882-12883

Liu Z, Ohsuna T, Terasaki O, et al. The first zeolite with threedimensional intersecting straight-channel system of 12-membered rings. Journal of the American Chemical Society. 2001. 123: 53705371

Madhusoodana C D, Das R N, Kameshima Y, et al. Preparation of ZSM5 zeolite honeycomb monoliths using microporous silica obtained from metakaolinite. Journal of Porous Materials. 2005. 12 (4): 273 280

Matsukata M, Osaki T, Ogura M, et al. Crystallization behavior of zeolite beta during steam-assisted crystallization of dry gel. Microporous and Mesoporous Materials. 2002. 56(1): 1-10

Mignoni M L, Petkowicz D I, Fernandes M N, et al. Synthesis of mordenite using kaolin as Si and Al source. Applied Clay Science. 2008. 41(1-2): 99-104

Prasetyoko D, Ramli Z, Endud S, et al. Conversion of rice husk ash to zeolite beta. Waste Management. 2006. 26(10): 1173-1179

Saxton R J and Zajacek J G. Method of making essentially silicic zeolite Beta. US 5554356. 1996

Serrano D P, Grieken R V , Sónchez P, et al. Crystallization mechanism of all-silica zeolite beta in fluoride medium. Microporous and Mesoporous Materials. 2001. 46: 35-46

Wadlinger R L, Kerr G T and Rosinski E J. Catalytic composition of a crystalline zeolite. US 3308069. 1967

Wan G F, Duan A J, Zhang Y, et al. Zeolite beta synthesized with acidtreated metakaolin and its application in diesel hydrodesulfurization. Catalysis Today. 2010. 149 (1-2): 69-75

Wan G F, Duan A J, Zhang Y, et al. Hydrodesulfurization of fluidized catalytic cracking diesel oil over NiW/AMB catalysts containing H-Type beta-zeolite in situ synthesized from kaolin material. Energy \& Fuels. 2009. 23(8): 3846-3852

Zhang Y, Gao W and Cui L S. The transformation of acid leached metakaolin to zeolite beta. Studies in Surface Science and Catalysis. 2007. 170: 420-425

(Edited by Zhu Xiuqin) 